\title{
Affinity capillary electrophoresis with laser induced fluorescence detection for thrombin analysis using nuclease-resistant RNA aptamers
}

\author{
Lihua Hao ${ }^{\mathrm{a}, \mathrm{b}}$, Yunlong Bai ${ }^{\mathrm{a}, \mathrm{c}}$, Hailin Wang ${ }^{\mathrm{a}, \mathrm{d}}$, Qiang Zhao ${ }^{\mathrm{a}, \mathrm{d}, *}$ \\ a State Key Laboratory of Environmental Chemistry and Ecotoxicology, Research Center for Eco-Environmental Sciences, Chinese Academy of Sciences, \\ Beijing 100085, China \\ ${ }^{\mathrm{b}}$ College of Chemistry and Chemical Engineering, Shanxi University, Taiyuan 030006, China \\ ${ }^{\mathrm{c}}$ Institute of Environmental Science, Shanxi University, Taiyuan 030006, China \\ d University of Chinese Academy of Sciences, Beijing 100049, China
}

\section{A R T I C L E I N F O}

\section{Article history:}

Received 19 September 2016

Received in revised form 30 October 2016

Accepted 10 November 2016

Available online 10 November 2016

\section{Keywords:}

RNA aptamer

Thrombin

Affinity binding

Laser induced fluorescence

Capillary electrophoresis

2 '-Fluoro modification

\begin{abstract}
A B S T R A C T
Aptamer affinity capillary electrophoresis coupled with laser-induced fluorescence (CE-LIF) combines the advantages of affinity aptamer, rapid CE separation, and high sensitivity detection. Here we reported an affinity CE-LIF assay for thrombin by using a fluorophore-labeled RNA aptamer containing 2'-fluoro modification in sugar rings of pyrimidine nucleotides ( $\mathrm{C}$ and $\mathrm{U}$ ) as affinity ligand. This RNA aptamer has high binding affinity, specificity and biostability. Thrombin at $0.2 \mathrm{nM}$ was successfully detected. This RNA aptamer allowed for the detection of thrombin spiked in diluted human serum sample due to the nuclease resistance. The RNA aptamer has comparable binding affinity to a 29-mer DNA aptamer for thrombin, and the binding site of the RNA aptamer on thrombin partially overlaps with the binding site of the 29-mer DNA aptamer on thrombin. It shows the nuclease-resistant RNA aptamers are promising in assays for thrombin.
\end{abstract}

(C) 2016 Elsevier B.V. All rights reserved.

\section{Introduction}

Affinity probe capillary electrophoresis (APCE) combines capillary electrophoresis separation and the affinity recognition [1-5]. This technique not only provides an efficient way to study molecular interactions and also allows to develop sensitive assays for targets by coupling with laser induced fluorescence (LIF) [5,6]. CELIF requires to label fluorophore onto the target or the affinity probes. Affinity CE-LIF has been applied to detection of a variety of targets in competitive or noncompetitive formats, showing advantages in only requiring trace amount of samples and affinity ligand, fast CE separation, high sensitivity, and good selectivity [1-6].

Aptamer affinity capillary electrophoresis applies aptamers as affinity ligands in CE separation [7,8]. The aptamers are single stranded nucleic acid selected from random library, which can bind with the targets with high binding affinity and selectivity $[9,10]$. As unique affinity ligands, aptamers show attractive fea-

\footnotetext{
* Corresponding author at: State Key Laboratory of Environmental Chemistry and Ecotoxicology, Research Center for Eco-Environmental Sciences, Chinese Academy of Sciences, Beijing 100085, China.

E-mail addresses: qiangzhao@rcees.ac.cn, chemzhaoq@hotmail.com (Q. Zhao).
}

tures, such as easy selection, facile labeling, and precise chemical synthesis, and they are promising in many applications [11-13]. These properties make aptamer favorable for affinity CE analysis as affinity probe. In aptamer affinity CE-LIF assay for proteins $[7,8]$, the aptamer is usually labeled with a fluorescent dye. As the aptamers usually have many negative charges and smaller molecular weight than proteins, the binding of aptamer on proteins with large size and less charged can significantly change the ratio of charge to mass of the labeled aptamer. Therefore, the aptamerprotein complex and the free aptamer has great differences in electrophoretic mobility, enabling the easy separation of aptamerprotein complex from the unbound aptamers in CE [13]. By using aptamer affinity CE-LIF, a few proteins and peptides have been successfully detected $[7,8,14-24]$, including thrombin [7,14-18,24], immunoglobin E (IgE) [7,15,16], platelet derived growth factor BB (PDGF-BB) and its isomers [16,19], human immunodeficiency virus type 1 reverse transcriptase (HIV-1 RT) [8,16,20], ricin [21], human erythropoietin- $\alpha$ [22], glucagon [23], amylin [23], and etc. Detection of multiple proteins has been achieved with aptamers in one CE separation [16]. In this assay, the dye-labeled aptamer probes against different protein targets appear at the same migration time because the aptamer probe has similar charge-size ratio [16]. The 
different protein-aptamer complex of multiple proteins are well isolated by changing the length of aptamers and modulating the charge-size ratio of the complex [16]. When CE separation is coupled with laser induced fluorescence polarization detection, the fluorescence polarization (anisotropy) provides additional information for the investigation of affinity binding and mapping the binding site of the aptamer on protein target [5,18,24]. In most of these aptamer-based affinity CE assays, DNA aptamer probes are usually used, while the affinity CE assays using RNA aptamers are still limited. Only few work reported the CE-LIF detection of protein using RNA aptamers. This is due to the usual poor stability of RNA aptamers, especially in the biological fluids. RNA aptamers can be fast degraded by RNAse. Haes et al. reported the detection of ricin using a dye-labeled RNA aptamers in free zone affinity CE format, allowing for the detection of ricin at $0.5 \mathrm{nM} \mathrm{[21].} \mathrm{Yi} \mathrm{et} \mathrm{al.}$ reported the use of RNA-Spiegelmer aptamers for CE analysis of amylin and glucagon, which are mirror-image aptamers and have high biostability [23].

Thrombin is a serine protease in blood, having multiple functions [25]. For CE-LIF analysis of thrombin using aptamers, only DNA aptamer-based assays are reported so far [7,14-18,24]. Two DNA aptamers are widely applied for human thrombin analysis. One has 15 bases (Apt-15, 5'-GGT TGG TGT GGT TGG-3') with weaker affinity $\left(K_{\mathrm{d}} \sim 100 \mathrm{nM}\right)$ [26], binding to the fibrinogen binding site of thrombin. The other 29-nt DNA aptamer (Apt-29, 5'-AGT CCG TGG TAG GGC AGG TTG GGG TGA CT-3') has high binding affinity $\left(K_{\mathrm{d}} \sim 0.5 \mathrm{nM}\right)$ [27], which binds to the heparin-binding site of human thrombin. These aptamers have been involved in many assays for human thrombin $[12,13,28,29]$. The weak binding affinity of Apt-15 makes the affinity CE analysis of thrombin using Apt-15 as affinity ligands challenging, and the complex peak of thrombinApt-15 is difficult to form when Apt-15 is used in affinity CE for thrombin detection $[7,14,15]$. In contrast, a good complex peak can be well isolated from the fluorophore-labeled aptamer probe during CE analysis of thrombin with Apt-29 as this aptamer has strong binding affinity [16-18,24]. RNA aptamers against thrombin have been also successfully selected [30,31]. One desirable 25-mer RNA aptamer (5'-GGG AAC AAA GCU GAA GUA CUU ACC C-3', named here Toggle-25) contains $2^{\prime}$-fluoro (F) modification in sugar ring of nucleotides $C$ and $U$ [31], which was selected to bind with human thrombin and porcine thrombin. This F modification in nucleotides greatly improves the resistance of the aptamer to nuclease degradation. Thus, Toggle-25 shows good stability in biological fluids, overcoming the limitation of unmodified RNA aptamers in poor stability [30]. Toggle-25 exhibits high binding affinity to human thrombin and porcine thrombin. The $K_{\mathrm{d}}$ of Toggle-25 is reported to be around $0.5 \mathrm{nM}$ for human thrombin, and the $K_{\mathrm{d}}$ for porcine thrombin is about $1.4 \mathrm{nM}$ [31]. From sequence analysis, it is proposed that Toggle-25 has a stem-loop secondary structure with an internal bulge (shown in Fig. 1), and the bulge is flanked by two short duplex regions [31]. The crystal structure of the complex of Toggle-25 and thrombin is already available, and it confirms the presence of stem-loop structure and shows an additional base pair formed between C11 and G16 and the existence of extensive $\pi-\pi$ stacking of bases [32]. The unique three-dimensional structure of Toggle-25 presents good shape complementarity to native surface of thrombin, allowing for the specific and tight interaction between thrombin and Toggle- 25 . Toggle- 25 has great potential in applications due to its high binding affinity and good stability.

The objective of this work is to report a CE-LIF assay for human thrombin using the nuclease-resistant RNA aptamer Toggle-25 as affinity ligand. We successfully achieved detection of human thrombin by using fluorophore-labeled Toggle- 25 as affinity ligand in affinity CE-LIF analysis. Thrombin as low as $0.2 \mathrm{nM}$ was detected. This assay also allowed for the detection of thrombin in diluted human serum samples due to the good resistance of Toggle-25 to

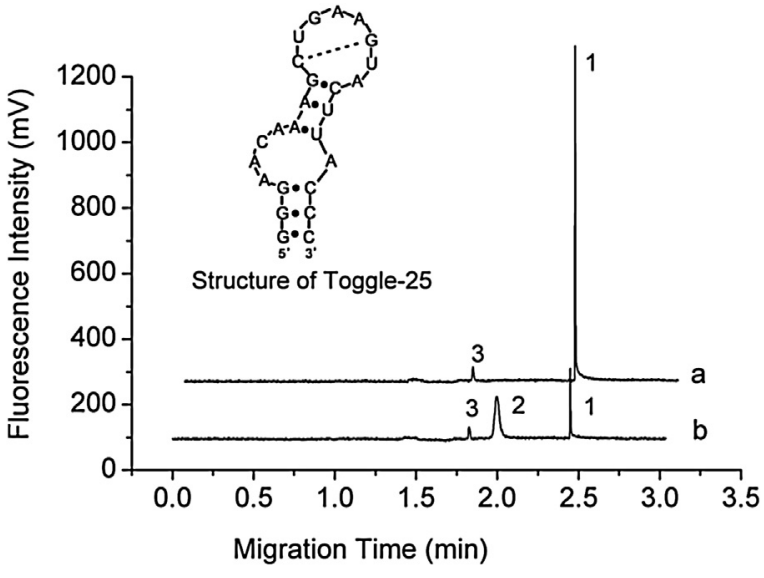

Fig. 1. Electropherograms of TMR-labeled Toggle-25 (Toggle-25-TMR) in absence of thrombin (a) and in presence of $10 \mathrm{nM}$ thrombin (b). Peak 1 was from the unbound Toggle-25-TMR, and Peak 2 was from the Toggle-25-TMR bound to thrombin. Peak 3 was from the free TMR dye of the internal standard. The proposed secondary structure of Toggle-25 was also shown in the inset.

nuclease degradation. We also explored the binding site of Toggle25 on thrombin in CE analysis. Toggle-25 competed with Apt-29 in the binding of thrombin, and the binding site of Toggle-25 on thrombin was partially overlapped with the binding site of DNA aptamer Apt-29 on thrombin. The binding site of Toggle-25 was different from the binding site of Apt-15 on thrombin as no competition between Apt-15 and Toggle- 25 was found. The good stability and high binding affinity of Toggle- 25 makes Toggle- 25 promising in assay developments and other applications.

\section{Materials and methods}

\subsection{Chemicals}

Human $\alpha$-thrombin was ordered from Haematologic Technologies Inc. Bovine serum albumin (BSA), lysozyme, and hemoglobin were purchased from Sigma. Unlabeled RNA aptamer Toggle-25, RNA aptamer Toggle-25 with tetramethylrhodamine (TMR) label on 5'-end, and the control RNA with TMR label on 5'-end (Toggle25: 5'-GGG AAC AAA GCU GAA GUA CUU ACC C-3'; Toggle-25-TMR: 5'-TMR-GGG AAC AAA GCU GAA GUA CUU ACC C-3'; Control-25TMR: 5'-TMR-GGG AAC AAA GCU GAA GUA CAA ACC C-3') were synthesized and purified by Takara Biotechnology (Dalian) Co., Ltd. (Dalian, China). TMR labeled DNA aptamers and unlabeled DNA aptamers were synthesized and purified by Sangon Biotech (Shanghai, China) (Apt-29-TMR: 5'-TMR-AGT CCG TGG TAG GGC AGG TTG GGG TGA CT-3'; Apt-15-TMR: 5'-TMR-GGT TGG TGT GGT TGG3'; Apt-29: 5'-AGT CCG TGG TAG GGC AGG TTG GGG TGA CT-3'; Apt-15: 5'-GGT TGG TGT GGT TGG-3'). Human serum sample was purchased from Zhongke Chenyu Biotechnology (Beijing, China). Solvents and other reagents were in analytical grade. Ultra-pure water $(18.2 \mathrm{M} \Omega \mathrm{cm}$ ) was obtained from a Purelab Ultra Elga Labwater system. TG buffer (25 mM Tris, $192 \mathrm{mM}$ glycine, pH 8.3) was filtered with a $0.22-\mu \mathrm{m}$ filter (Millipore, Bedford, USA) and used as separation buffer.

\subsection{Apparatus}

A previously reported laboratory-built capillary electrophoresis laser induced fluorescence system was used for separation and detection $[18,24,33]$. Briefly, uncoated fused silica capillaries were used for separation ( $40 \mathrm{~cm}$ in length, $365 \mu \mathrm{m}$ o.d., $25 \mu \mathrm{m}$. i.d., Yongnian Optical Fiber, Hebei, China). The detection window was $34 \mathrm{~cm}$ far from the inlet of the capillary. A green He-Ne laser $(543.5 \mathrm{~nm}$, 
$1 \mathrm{~mW}$, Melles Griot, Irvine, CA, USA) was used for excitation of TMR, and fluorescence was detected at $575 \mathrm{~nm}$. The fluorescence was recorded by a photomultiplier tube (PMT) (Model R3896, Hamamatsu Photonics, Japan). The signal from PMT was collected by a HW-2000 chromatographic workstation (Qianpu Software Co., Shanghai, China). The data was recorded with a frequency of $60 \mathrm{~Hz}$.

\subsection{CE procedure}

Following each electrophoresis run, the capillary was flushed sequentially with $20 \mathrm{mM} \mathrm{NaOH}(5 \mathrm{~min})$, water ( $3 \mathrm{~min}$ ), and TG buffer ( $5 \mathrm{~min}$ ). TMR labeled aptamer probes were heated at $85^{\circ} \mathrm{C}$ for $3 \mathrm{~min}$, and then cooled in ice. $10 \mathrm{nM}$ TMR labeled aptamer probes were mixed with varying concentrations of thrombin in sample buffer solution ( $10 \mathrm{mM}$ Tris- $\mathrm{HCl}(\mathrm{pH} 7.5)+1 \mathrm{mM} \mathrm{MgCl}_{2}+1 \mathrm{mg} / \mathrm{mL}$ $\mathrm{BSA}$ ), and a free TMR dye was also added in the sample and used as an internal standard (IS) for CE separation. After incubation of the sample for $30 \mathrm{~min}$ in ice, the sample was then injected by applying $15 \mathrm{kV}$ voltage on the ends of capillary for $5 \mathrm{~s}$. CE separation was performed by applying a voltage of $20 \mathrm{kV}$ at room temperature.

\section{Results and discussion}

\subsection{Assay feasibility}

First we tested the feasibility of CE-LIF analysis of human thrombin (molecular weight $\sim 36.7 \mathrm{kD}$ ) with the TMR-labeled Toggle-25 RNA aptamer (molecular weight $\sim 9 \mathrm{kD}$ ). TMR-labeled Toggle-25 $(10 \mathrm{nM})$ was incubated in a sample buffer $(10 \mathrm{mM}$ Tris- $\mathrm{HCl}, \mathrm{pH}$ 7.5) in the absence of thrombin or in the presence of thrombin $(10 \mathrm{nM})$, and then injected into a capillary ( $25 \mu \mathrm{m}$ i.d., total length: $40 \mathrm{~cm}$, effective length: $34 \mathrm{~cm}$ ) by applying $15 \mathrm{kV}$ voltage for $5 \mathrm{~s}$. CE separation was conducted in TG buffer by applying $20 \mathrm{kV}$ voltage. Fig. 1 shows the electropherograms of CE separation of TMR labeled Toggle-25 (Toggle-25-TMR) in absence of thrombin or in the presence of thrombin. A free TMR dye was used as an internal standard (IS) in CE separation, and it appeared at around $1.7 \mathrm{~min}$. In absence of thrombin, a sharp peak of TMR-labeled aptamer was observed at around $2.5 \mathrm{~min}$ (curve a). In presence of thrombin, the peak of free aptamer probe significantly decreased in signal intensity, and a new peak appeared at about 2.0 min (curve b), which was the complex peak of thrombin and Toggle-25-TMR. The result shows the affinity complex is well isolated from free Toggle-25TMR due to the difference of charge to mass ratio of free aptamer and aptamer-thrombin complex and the strong binding of Toggle25-TMR to thrombin. Therefore, it is feasible to develop CE-LIF assay to analyze thrombin with TMR-labeled Toggle-25 and investigate the interaction between Toggle- 25 and thrombin.

\subsection{Effects of metal ions in sample buffer and separation buffer}

The reported selection buffer for Toggle-25 was the solution containing $20 \mathrm{mM}$ HEPES ( $\mathrm{pH} 7.4$ ), $150 \mathrm{mM} \mathrm{NaCl}, 2 \mathrm{mM} \mathrm{CaCl}_{2}$, and $0.01 \%$ BSA [31]. When HEPES (20 mM, pH 7.4) solution was used as sample buffer in CE analysis of thrombin with Toggle-25-TMR, poor CE separation was observed $[7,15]$. We chose Tris- $\mathrm{HCl}$ as sample buffer in our experiments as previous work showed this condition allowed for good separation of aptamer and aptamerprotein complex $[8,16,18,19,24]$. We then investigated the effects of metal ions in sample buffer $(10 \mathrm{mM}$ Tris- $\mathrm{HCl}, \mathrm{pH} 7.5)$ on the performance of separation of complex of thrombin and Toggle-25TMR. We analyzed thrombin-aptamer complex in sample buffer containing varying concentrations of $\mathrm{MgCl}_{2}$. When $1 \mathrm{mM} \mathrm{MgCl} 2$ was present in sample buffer, the peak area of complex increased remarkably, and further increase of $\mathrm{MgCl}_{2}$ did not cause a large increase of complex peak area (shown in Fig. 2). The addition of

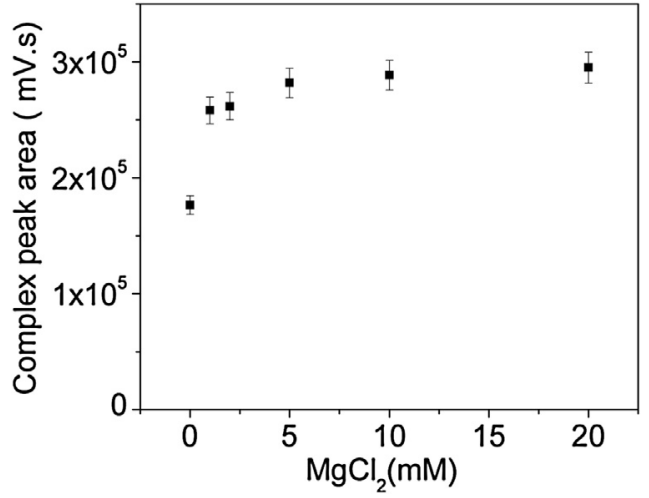

Fig. 2. The effect of $\mathrm{MgCl}_{2}$ in sample buffer ( $10 \mathrm{mM}$ Tris- $\mathrm{HCl}, \mathrm{pH}$ 7.5) on the peak area of complex of thrombin $(10 \mathrm{nM})$ and Toggle-25-TMR (10 nM).

$2 \mathrm{mM} \mathrm{CaCl}_{2}$ in sample buffer also made the complex peak larger (shown in Fig. S1 in Supplementary material), but the use of $\mathrm{MgCl}_{2}$ in sample buffer gave better results. $\mathrm{MgCl}_{2}$ and $\mathrm{CaCl}_{2}$ may help the aptamer to form a right structure for binding to thrombin [31], and the difference effects of $\mathrm{MgCl}_{2}$ and $\mathrm{CaCl}_{2}$ may be due to the properties of the divalent metal ions. The crystal structure of the complex of Toggle-25 and thrombin also shows the existence of $\mathrm{Mg}^{2+}$ coordinating nonbridging oxygen atoms of phosphates on two nucleotides of the aptamer, and it is expected that $\mathrm{Ca}^{2+}$ can play similar function [32].

The presence of $\mathrm{NaCl}$ ranging from $2 \mathrm{mM}$ to $10 \mathrm{mM}$ in sample buffer allowed for higher complex peak area (Fig. S2 in Supplementary material). When $\mathrm{NaCl}$ concentration was higher than $10 \mathrm{mM}$, the complex peak area decreased and the complex peak became closer to the free aptamer peak. The addition of $\mathrm{NaCl}$ (less than $20 \mathrm{mM}$ ) in the sample buffer solution containing $1 \mathrm{mM} \mathrm{MgCl} 2$ did not cause significant effects on the complex peak area, but the complex peak become closer to the peak of free aptamer probe with increase of $\mathrm{NaCl}$. High concentration of $\mathrm{NaCl}$ in sample buffer is not favorable for $\mathrm{CE}$ analysis though the selection buffer for Toggle-25 contained $150 \mathrm{mM} \mathrm{NaCl}$. The influence of $\mathrm{KCl}$ in sample buffer on the $\mathrm{CE}$ analysis was similar to the effect of $\mathrm{NaCl}$ in sample buffer. We chose the Tris- $\mathrm{HCl}$ buffer ( $10 \mathrm{mM}, \mathrm{pH} 7.5$ ) containing $1 \mathrm{mM} \mathrm{MgCl}_{2}$ and $1 \mathrm{mg} / \mathrm{mL}$ BSA as sample buffer in our study.

The addition of $1 \mathrm{mM} \mathrm{MgCl} 2$ in TG separation buffer caused the complex peak and free aptamer peak disappeared in the tested time range due to the change of EOF caused by $\mathrm{MgCl}_{2}$, which significantly slow down the separation [33]. With increase of $\mathrm{NaCl}$ in TG separation buffer, the complex peak became small (Fig. 3). When $10 \mathrm{mM} \mathrm{NaCl}$ existed, the complex peak was significantly decreased. Finally, we chose TG buffer without containing $\mathrm{NaCl}$ and $\mathrm{MgCl}_{2}$ as separation buffer.

\subsection{Detection of thrombin with CE-LIF using Toggle-25-TMR}

At the optimized condition, we detected varying concentrations of thrombin with CE-LIF using TMR labeled Toggle- 25 as an affinity probe. Fig. 4A shows electropherograms of analysis of thrombin at varying concentrations ranging from $0 \mathrm{nM}$ to $100 \mathrm{nM}$. With increase of thrombin concentration, the complex peak at around 2 min increased, while the peak of free aptamer probe at around 2.5 min decreased. The peak area of the complex peak shows linear relationship towards the concentration of thrombin in the range from 0.2 to $10 \mathrm{nM}\left(\mathrm{y}=28366 \mathrm{x}+30887, R^{2}=0.998\right)$ (Fig. 4B). As low as $0.2 \mathrm{nM}$ thrombin was detected. When higher concentrations of thrombin (larger than $10 \mathrm{nM}$ ) was analyzed, the obtained complex peak area reached a plateau level, because almost all of aptamer probe $(10 \mathrm{nM})$ was bound to thrombin. By increasing the amount of 


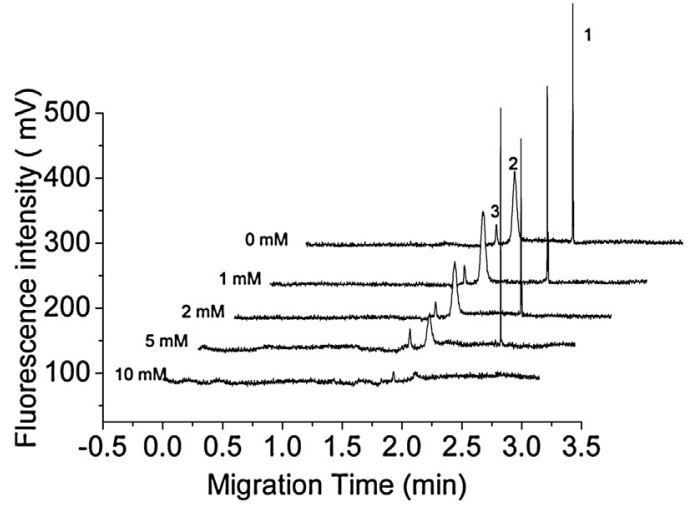

Fig. 3. Influence of $\mathrm{NaCl}$ in $\mathrm{TG}$ separation buffer on the separation of Toggle- 25 and complex of thrombin and Toggle-25. From top curve to bottom curve, the concentrations of $\mathrm{NaCl}$ in TG buffer were $0,1,2,5$, and $10 \mathrm{mM}$, respectively. Peak 1 was from the unbound Toggle-25-TMR, and Peak 2 was from the Toggle-25-TMR bound to thrombin. Peak 3 was from the free TMR dye of the internal standard.
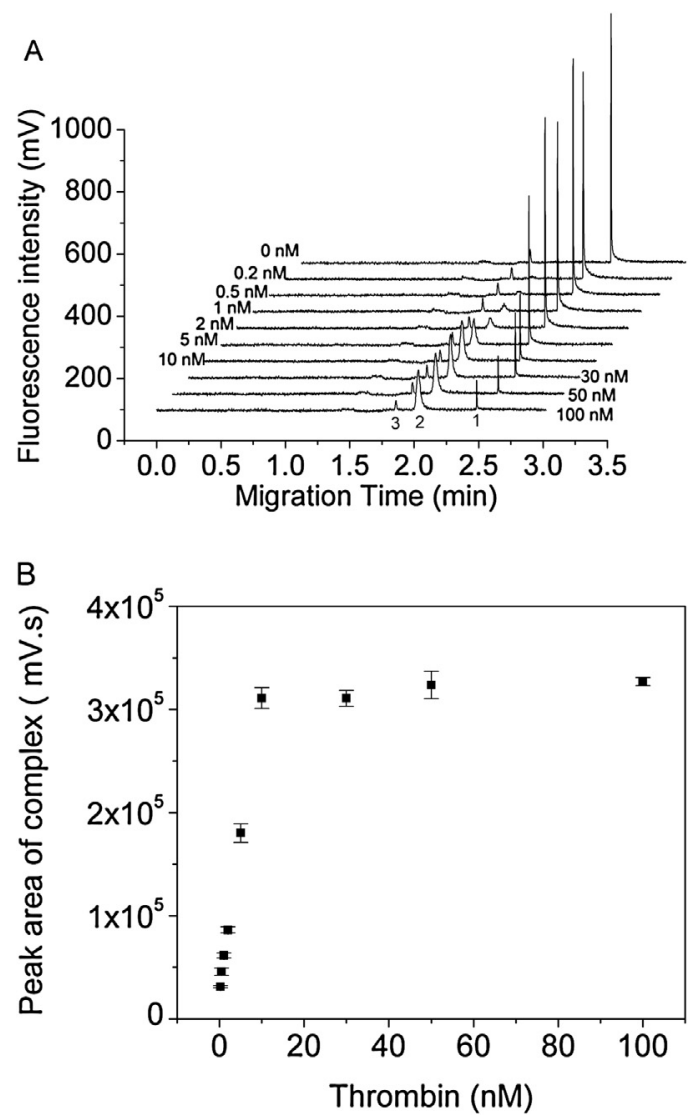

Fig. 4. CE-LIF detection of thrombin using TMR labeled Toggle-25. (A) Electropherograms of Toggle-25-TMR in presence of varying concentrations of thrombin. From top curve to the bottom curve the corresponding concentrations of thrombin were $0,0.2,0.5,1,2,5,10,30,50$, and $100 \mathrm{nM}$. Peak 1 was from the unbound Toggle-25TMR, and Peak 2 was from the Toggle-25-TMR bound to thrombin. Peak 3 was from the free TMR dye of the internal standard. (B) The relationship between the peak area of complex and the concentrations of thrombin.

aptamer probe, the upper detection range can be further extended. When 50 nM aptamer probe was used, the linear detection range for thrombin was extended to $50 \mathrm{nM}\left(\mathrm{y}=24189 \mathrm{x}+45729, R^{2}=0.989\right)$ (Fig. S3 in Supplementary material).

As comparison, we also made CE analysis of thrombin with TMR labeled DNA aptamers, including TMR labeled Apt-15 (Apt15-TMR) and TMR labeled Apt-29 (Apt-29-TMR). When 10 nM TMR labeled Apt-15 was used as an affinity probe, we did not observe a complex peak in CE separation when thrombin at $10 \mathrm{nM}$ was present, which was caused by the weak binding affinity of Apt15. This result is consistent with the previous report $[7,14,15]$. The complex of thrombin and Apt-15 fast dissociated during CE separation due to the weak binding affinity of Apt-15 [7,14,15]. A rapid separation and the use of high concentrations of aptamer probe and thrombin may help the formation of the complex of thrombin and Apt-15 [7,14,15].

When TMR labeled DNA Apt-29 was used as an affinity probe, a good complex peak was obtained, and thrombin was detected with this TMR-labeled Apt-29 (Fig. S4 in Supplementary material) [16-18]. For TMR-labeled Apt-29, the peak area of the complex peak shows linear relationship with the concentration of thrombin $\left(y=49152 x+26622, R^{2}=0.991\right)$ in the range from $0.5 \mathrm{nM}$ to $10 \mathrm{nM}$. The detection limit was about $0.5 \mathrm{nM}$. It indicates that Toggle25 and Apt-29 both allow sensitive detection of thrombin due to good binding affinity to thrombin, showing better performance in CE-LIF detection of thrombin than the Apt-15 that has weak binding affinity. Compared with the previous report of CE-LIF analysis of thrombin using DNA aptamers, the sensitivity of our assay is comparable to or better than that reported (shown in Table S1) [7,14-18]. One possible limitation for Toggle-25 is relatively high cost of synthesis of the RNA aptamer with modification in sugar rings of nucleotides. In CE-LIF analysis, only trace amount of dyelabeled Toggle-25 is needed, so the high cost of RNA aptamer is still acceptable. It is expected that the cost of synthesis of RNA can be reduced with the development of synthesis technology.

We then assessed the selectivity of CE-LIF analysis of human thrombin using TMR-labeled Toggle-25. We tested other proteins $(100 \mathrm{nM})$ along with thrombin $(10 \mathrm{nM})$. When TMR-labeled Toggle25 incubated with prothrombin, lysozyme, IgG, or hemoglobin, no complex peak was observed (Fig. S5 in Supplementary material), showing these tested proteins did not bind to the aptamer. The presence of lysozyme, IgG, or hemoglobin in the sample mixture of thrombin and TMR-labeled Toggle-25 also did not cause interference for analysis of thrombin using TMR-labeled Toggle-25. This result shows the CE-LIF assay for thrombin has good selectivity. As Toggle-25 is selected to bind with human thrombin and porcine thrombin with high binding affinity [31], it is expected that the presence of porcine thrombin can also give complex peak. The CE-LIF assay here can also be used for the detection of porcine thrombin.

We also tested the specificity of the sequence of Toggle-25 in affinity binding to thrombin. We replaced two $U$ bases in Toggle-25 into two A bases, obtaining a control RNA (Control25), 5'-GGGAACAAAGCUGAAGUACAAACCC-3'. The underline part shows the mutation part in Control-25. Using TMR labeled Control25 (Control-25-TMR) as a probe, we ran the same CE analysis for thrombin at the same condition, we did not find the complex peak of thrombin and Control-25-TMR. The result shows the binding between thrombin and Toggle-25 is highly dependent in sequence, and the mutation of only two bases in Toggle-25 causes the complete loss of binding affinity, and the result is in agreement with the previous report [31].

To show the applicability of the Toggle-25 for detection of thrombin in complex sample matrix, we analyzed the thrombin spiked in diluted human serum sample. Human serum sample was 50 -fold diluted with sample buffer solution. Thrombin was spiked into the 50-fold diluted serum sample and incubated with TMRlabeled Toggle-25. Thrombin could still be detected in the 50 -fold diluted human serum sample (shown in Fig. S6 in Supplementary material). The complex peak area is linear with the concentration of thrombin ranging from 0.2 to $10 \mathrm{nM}(\mathrm{y}=29030 \mathrm{x}+44884$, $R^{2}=0.987$ ). The obtained sensitivity was close to that obtained in sample buffer. We further tested the stability of Toggle-25 in the 


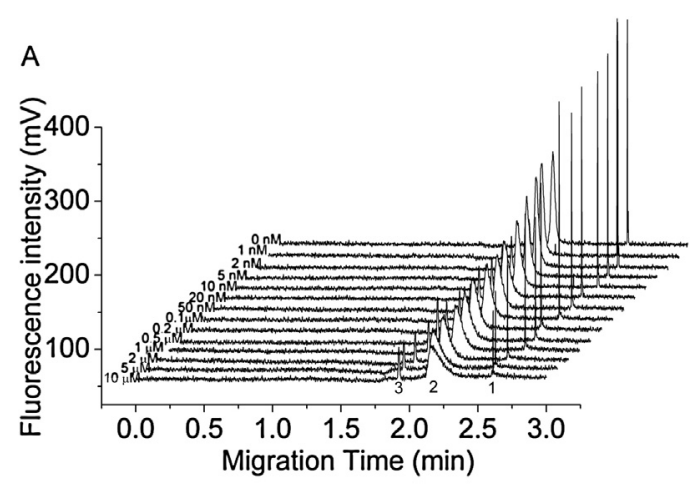

$B$

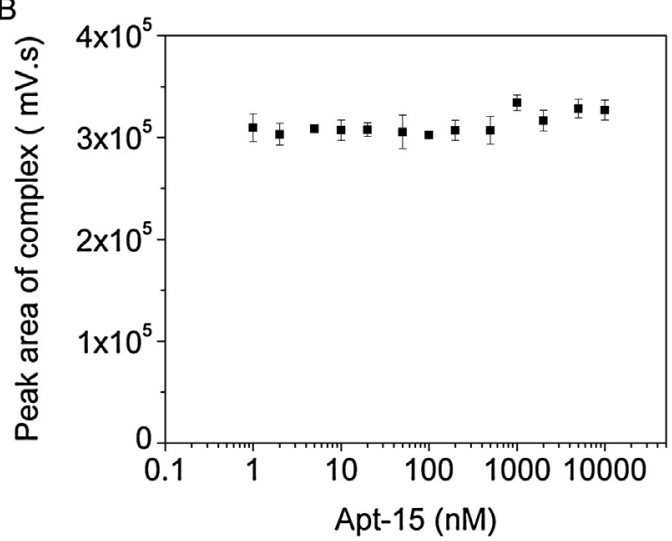

Fig. 5. Investigation of the effect of unlabeled DNA aptamer Apt-15 on the interaction between Toggle-25-TMR and thrombin. (A) The electropherograms of Toggle-25-TMR $(10 \mathrm{nM})$ and thrombin $(10 \mathrm{nM})$ in the presence of varying concentrations of unlabeled Apt-15 (from top curve to the bottom curve, the corresponding concentrations of Apt-15 were 0, 1, 2, 5, 10, 20, 50, 100, 200, 500, 1000, 2000, 5000, $10000 \mathrm{nM}$, respectively) Peak 1 was from the unbound Toggle-25-TMR, and Peak 2 was from the Toggle-25-TMR bound to thrombin. Peak 3 was from the free TMR dye of the internal standard. (B) The relationship between peak area of complex of the Toggle-25-TMR and thrombin and the concentrations of Apt-15.

diluted serum (Fig. S7 in Supplementary material) for thrombin binding in CE-LIF analysis. The peak area of complex of thrombin and Toggle-25 in CE-LIF analysis was not significantly changed when TMR-labeled Toggle-25 was incubated with thrombin in dilute serum even for $18 \mathrm{~h}$ at $4{ }^{\circ} \mathrm{C}$ or at room temperature. The results show that the TMR-labeled Toggle- 25 is stable in the diluted serum sample due to the fluoro modification on $2^{\prime}$ position of sugar ring of $C$ and $U$ [31], which shows advantages over the RNA aptamers without modification. As previously reported [31], such fluoro modification in pyrimidine nucleotides makes the modified RNA oligos can have better stability in biological fluids than DNA oligos.

\subsection{Investigation of binding sites of Toggle-25 on thrombin}

To investigate whether Toggle-25 competes with DNA aptamers (Apt-15 and Apt-29) in affinity binding to thrombin and to explore the difference of binding sites of the Toggle-25 and the DNA aptamers on thrombin, we further tested the effect of unlabeled DNA aptamers (Apt-15 and Apt-29) on the interaction between Toggle-25-TMR and thrombin by CE-LIF analysis. We incubated varying concentrations of unlabeled DNA aptamers (Apt-15 or Apt-29) with $10 \mathrm{nM}$ thrombin and $10 \mathrm{nM}$ Toggle-25-TMR, and conducted CE-LIF analysis. The concentration of Apt-15 ranged from $1 \mathrm{nM}$ to $10 \mu \mathrm{M}$. As Fig. 5 shows, the addition of Apt-15 makes the complex peak wide and tailing, and the peak height of complex peak decreased with the increase of Apt-15. However, the total peak area of complex peak was not changed with the addition of Apt-15
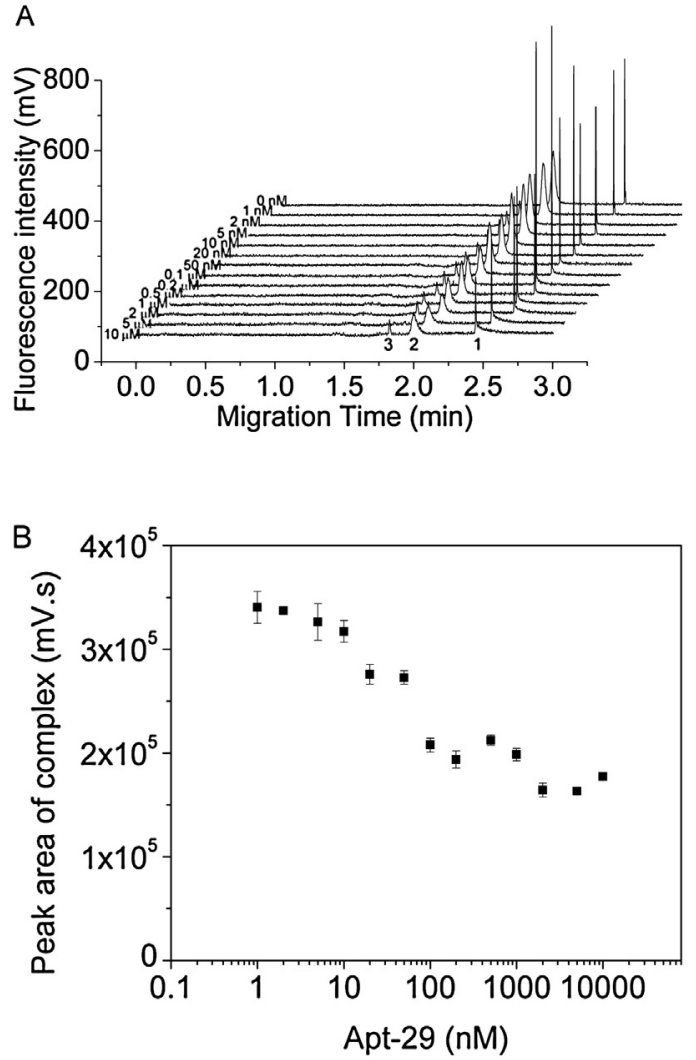

Fig. 6. Investigation of the effect of unlabeled DNA aptamer Apt-29 on the interaction between Toggle-25-TMR and thrombin. (A) The electropherograms of TMR-Toggle-25 $(10 \mathrm{nM})$ and thrombin $(10 \mathrm{nM})$ in the presence of varying concentrations of Apt-29 (from top curve to the bottom curve, the corresponding concentrations of Apt-29 were 0, 1, 2, 5, 10, 20, 50, 100, 200, 500, 1000, 2000, 5000, $10000 \mathrm{nM}$, respectively) Peak 1 was from the unbound Toggle-25-TMR, and Peak 2 was from the Toggle-25-TMR bound to thrombin. Peak 3 was from the free TMR dye of the internal standard. (B) The relationship between peak area of the complex of Toggle-25-TMR and thrombin and the concentrations of unlabeled Apt-29.

(Fig. 5B). It is possible that a sandwich complex of Apt-15, thrombin, and Toggle- 25 is formed. The sandwich complex contains two aptamers, so it has more negative charges and moves closer to the free aptamer peak during separation [17]. Due to the dissociation of Apt-15 from the sandwich complex during CE separation, a tailing and wide complex peak was observed. The migration time of the front of the complex peak is still close to that of the complex peak thrombin-Toggle-25. Thus, the result suggests the Apt-15 does not compete with Toggle-25. As the non-competition of Apt-15 with Toggle-25-TMR, the binding site of Apt-15 is different from the binding site of Toggle-25 on thrombin. It has been known that Apt-15 binds to the fibrinogen-binding site of thrombin [26,27]. Therefore, Toggle-25 does not bind with the fibrinogen-binding site of thrombin.

In contrast, the addition of unlabeled aptamer Apt-29 ranged from $1 \mathrm{nM}$ to $10 \mu \mathrm{M}$ did not change the migration time of the complex peak of Toggle-25-TMR and thrombin (shown in Fig. 6A). The height and peak area of the complex peak of Toggle-25-TMR and thrombin significantly decreased with the increase of Apt-29 (shown in Fig. 6B). It shows that Apt-29 competes with the Toggle25 in the affinity binding to thrombin. The competition of Apt-29 to Toggle-25 suggests the binding site of Toggle-25 is overlapped with the binding site of Apt-29 on thrombin. As previous study shows Apt-29 binds with the heparin-binding site [27], the binding site of Toggle-25 on thrombin is possibly close to the heparin-binding site. This result is in agreement with the previous report [31,32,34]. The characterized crystal structure of complex thrombin and 
Toggle-25 also proves the binding site of Toggle-25 is near the heparin binding site of thrombin [32]. It is noted that the 1000-fold Apt-29 $(10 \mu \mathrm{M})$ added only made the peak area of the complex peak decreased about $49 \%$. As comparison, when varying concentrations of unlabeled Toggle-25 was added in the sample solution containing $10 \mathrm{nM}$ thrombin and $10 \mathrm{nM}$ Toggle-25-TMR, the complex peak of Toggle-25-TMR and thrombin decreased with the addition of unlabeled Toggle-25, and the complex peak disappeared as $500 \mathrm{nM}$ unlabeled Toggle-25 was present in sample solution (Fig. S8 in Supplementary material). It suggests that the bound Toggle-25-TMR was completely displaced by unlabeled Toggle-25. Considering the fact that high concentration of Apt-29 $(10 \mu \mathrm{M})$ did not totally displace the bound Toggle-25-TMR from thrombin, it indicates the binding site of Toggle-25 on thrombin is very close to that of Apt29 on thrombin, but their binding sites are not completely the same, which is in agreement with the results of the characterized crystal structures of Toggl-25-thrombin complex and Apt-29-thrombin complex $[32,35]$.

\section{Conclusion}

In summary, we reported a CE-LIF assay for thrombin using dye-labeled nuclease resistant RNA aptamer Toggle-25, which contained 2 '-fluoro modification in sugar ring of $C$ and $U$ nucleotides. A good separation of complex of thrombin-aptamer and free aptamer was achieved in CE due to the high binding affinity of Toggle25 and the difference of charge to mass ratio. We achieved the detection of thrombin as low as $0.2 \mathrm{nM}$ in this aptamer affinity CE approach. The RNA aptamer probe allowed for analysis of thrombin spiked in serum samples due to the high biostability of the RNA aptamers, overcoming the limitation of unmodified RNA aptamers suffering from degradation of nuclease in biological fluids. We also attempted to investigate the binding site of Toggle- 25 of thrombin by using the DNA aptamers to compete with Toggle- 25 probe during CE-LIF analysis. Toggle-25 competed with DNA aptamer Apt-29 in binding to thrombin, the binding site of Toggle- 25 was close to the heparin-binding site of thrombin. The Toggle-25 RNA aptamer shows promise in other analytical applications. A wide application of nuclease-resistant RNA aptamers to a variety of targets can be expected.

\section{Acknowledgements}

This work was supported by National Natural Science Foundation of China (Grant No. 21435008, 21575153, 21222503) and the Strategic Priority Research Program of the Chinese Academy of Sciences (XDB14030200).

\section{Appendix A. Supplementary data}

Supplementary data associated with this article can be found, in the online version, at http://dx.doi.org/10.1016/j.chroma.2016.11. 011.

\section{References}

[1] S. Hu, N.J. Dovichi, Capillary electrophoresis for the analysis of biopolymers, Anal. Chem. 74 (2002) 2833-2850.

[2] R.K. Harstad, A.C. Johnson, M.M. Weisenberger, M.T. Bowser, Capillary electrophoresis, Anal. Chem. 88 (2016) 299-319.

[3] M. Gayton-Ely, T.J. Pappas, L.A. Holland, Probing affinity via capillary electrophoresis: advances in 2003-2004, Anal. Bioanal. Chem. 382 (2005) 570-580.

[4] H.M. Albishri, S.E. Deeb, N. AlGarabli, R. AlAstal, H.A. Alhazmi, M. Nachbar, D.A.bd El-Hady, H. Watzig, Recent advances in affinity capillary electrophoresis for binding studies, Bioanalysis 6 (2014) 3369-3392.

[5] V. Pavski, X.C. Le, Ultrasensitive protein-DNA binding assays, Curr. Opin. Biotechnol. 14 (2003) 65-73.
[6] E. Ban, E. Joo Song, Recent developments and applications of capillary electrophoresis with laser-induced fluorescence detection in biological samples, J. Chromatogr. B 929 (2013) 180-186.

[7] I. German, D.D. Buchanan, R.T. Kennedy, Aptamers as ligands in affinity probe capillary electrophoresis, Anal. Chem. 70 (1998) 4540-4545.

[8] V. Pavski, X.C. Le, Detection of human immunodeficiency virus type 1 reverse transcriptase using aptamers as probes in affinity capillary electrophoresis, Anal. Chem. 73 (2001) 6070-6076.

[9] A.D. Ellington, J.W. Szostak, In vitro selection of RNA molecules that bind specific ligands, Nature 346 (1990) 818-822.

[10] C. Tuerk, L. Gold, Systematic evolution of ligands by exponential enrichment: RNA ligands to bacteriophage T4 DNA polymerase, Science 249 (1990) 505-510.

[11] S. Klussmann (Ed.), The Aptamer Handbook, Functional Oligonucleotides and Their Applications, Wiley-VCH, Weinheim, 2006.

[12] J. Liu, Z. Cao, Y. Lu, Functional nucleic acid sensors, Chem. Rev. 109 (2009) 1948-1998.

[13] F. Li, H. Zhang, Z. Wang, A.M. Newbigging, M.S. Reid, X.F. Li, X.C. Le, Aptamers facilitating amplified detection of biomolecules, Anal. Chem. 87 (2015) 274-292.

[14] C.C. Huang, Z. Cao, H. Chang, W. Tan, Protein-protein interaction studies based on molecular aptamers by affinity capillary electrophoresis, Anal. Chem. 76 (2004) 6973-6981.

[15] D.D. Buchanan, E.E. Jameson, J. Perlette, A. Malik, R.T. Kennedy, Effect of buffer, electric field, and separation time on detection of aptamer-ligand complexes for affinity probe capillary electrophoresis, Electrophoresis 24 (2003) 1375-1382.

[16] H. Zhang, X.-F. Li, X.C. Le, Tunable aptamer capillary electrophoresis and its application to protein analysis, J. Am. Chem. Soc. 130 (2008) 34-35.

[17] Y. Li, L. Guo, F. Zhang, Z. Zhang, J. Tang, J. Xie, High-sensitive determination of human $\alpha$-thrombin by its 29-mer aptamer in affinity probe capillary electrophoresis, Electrophoresis 29 (2008) 2570-2577.

[18] M. Song, Y. Zhang, T. Li, Z. Wang, J. Yin, H. Wang, Highly sensitive detection of human thrombin in serum by affinity capillary electrophoresis laser-induced fluorescence polarization using aptamers as probes, J. Chromatogr. A 1216 (2009) 873-878

[19] H. Zhang, X.-F. Li, X.C. Le, Differentiation and detection of PDGF isomers and their receptors by tunable aptamer capillary electrophoresis, Anal. Chem. 81 (2009) 7795-7800.

[20] H. Wang, M. Lu, X.C. Le, DNA-driven focusing for protein-DNA binding assays using capillary electrophoresis, Anal. Chem. 77 (2005) 495-4950.

[21] A.J. Haes, B.C. Giordano, G.E. Collins, Aptamer-based detection and quantitative analysis of ricin using affinity probe capillary electrophoresis, Anal. Chem. 78 (2006) 3758-3764.

[22] R. Shen, L. Guo, Z. Zhang, Q. Meng, J. Xie, Highly sensitive determination of recombinant human erythropoietin-alpha in aptamer-based affinity probe capillary electrophoresis with laser-induced fluorescence detection, J. Chromatogr. A 1217 (2010) 5635-5641.

[23] L. Yi, X. Wang, L. Bethge, S. Klussmann, M.G. Roper, Noncompetitive affinity assays of glucagon and amylin using mirror-image aptamers as affinity probes, Analyst 141 (2016) 1939-1946.

[24] D. Zhang, M. Lu, H. Wang, Fluorescence anisotropy analysis for mapping aptamer-protein interaction at the single nucleotide level, J. Am. Chem. Soc. 133 (2011) 9188-9191.

[25] M.E. Maragoudakis, N.E. Tsopanoglou, Thrombin: Physiology and Disease, Springer Science, New York, 2009.

[26] L.C. Bock, L.C. Griffin, J.A. Latham, E.H. Vermaas, J.J. Toole, Selection of single-stranded DNA molecules that bind and inhibit human thrombin, Nature 355 (1992) 564-566.

[27] D.M. Tasset, M.F. Kubik, W. Steiner, Oligonucleotide inhibitors of human thrombin that bind distinct epitopes, J. Mol. Biol. 272 (1997) 688-698.

[28] B. Deng, Y. Lin, C. Wang, F. Li, Z. Wang, H. Zhang, X.F. Li, X.C. Le, Aptamer binding assays for proteins: the thrombin example-a review, Anal. Chim. Acta 837 (2014) 1-15.

[29] N. Deng, B. Jiang, Y. Chen, Z. Liang, L. Zhang, Y. Liang, K. Yang, Y. Zhang Aptamer-conjugated gold functionalized graphene oxide nanocomposites for human $\alpha$-thrombin specific recognition, J. Chromatogr. A 1427 (2016) 16-21.

[30] M.F. Kubik, A.W. Stephens, D. Schneider, R.A. Marlar, D. Tasset, High-affinity RNA ligands to human $\alpha$-thrombin, Nucleic Acids Res. 22 (1994) 2619-2626.

[31] R. White, C. Rusconi, E. Scardino, A. Wolberg, J. Lawson, M. Hoffman, B. Sullenger, Generation of species cross-reactive aptamers using toggle SELEX, Mol. Ther. 4 (2001) 567-573.

[32] S.B. Long, M.B. Long, R.R. White, B.A. Sullenger, Crystal structure of an RNA aptamer bound to thrombin, RNA 14 (2008) 2504-2512.

[33] T. Li, D. Zhang, W. Luo, M. Lu, Z. Wang, Y. Song, H. Wang, Metal cation mediated-capillary electrophoresis of nucleic acids, Anal. Chem. 82 (2010) 487-490.

[34] M.L. Jeter, L.V. Ly, Y.M. Fortenberry, H.C. Whinna, R.R. White, C.P. Rusconi, B.A. Sullenger, F.C. Church, RNA aptamer to thrombin binds anion-binding exosite- 2 and alters protease inhibition by heparin-binding serpins, FEBS Lett. 568 (2004) 10-14

[35] I.R. Krauss, A. Pica, A. Merlino, L. Mazzarella, F. Sica, Duplex-quadruplex motifs in a peculiar structural organization cooperatively contribute to thrombin binding of a DNA aptamer, Acta Cryst. D69 (2013) 2403-2411. 